\title{
Asthma control and psychological health in pediatric severe asthma: Why is child phenotyping necessary? Suggestions from a multidisciplinary "Stress-Asthma Working Group"
}

Gennaro Liccardi ${ }^{1}$, Manlio Milanese ${ }^{2}$, Maria Beatrice Bilo's, Matteo Martini ${ }^{4}$, Francesco Habetswallner ${ }^{5}$, Maria Vittoria Liccardi ${ }^{6}$, and Paola Rogliani ${ }^{7}$

${ }^{1}$ University of Rome Tor Vergata

${ }^{2}$ Hospital Santa Corona Pietra Ligure

${ }^{3}$ Università Politecnica delle Marche

${ }^{4}$ Chiesi Farmaceutici SpA

${ }^{5}$ Ospedale Cardarelli

${ }^{6}$ Psychologist

${ }^{7}$ Universita degli Studi di Roma Tor Vergata

April 18, 2021

\begin{abstract}
An increased basal cholinergic tone, induced by psychological health impairment, could be a likely link between psychological/psychiatric disorders and severe bronchial asthma in children, as well as in adolescents and adults. This link can explain the high rate of anxiety in asthmatics in comparison to non-asthmatics of all ages.
\end{abstract}

\section{Hosted file}

Manuscript_24mar.pdf available at https://authorea.com/users/408594/articles/518534-asthmacontrol-and-psychological-health-in-pediatric-severe-asthma-why-is-child-phenotypingnecessary-suggestions-from-a-multidisciplinary-stress-asthma-working-group 


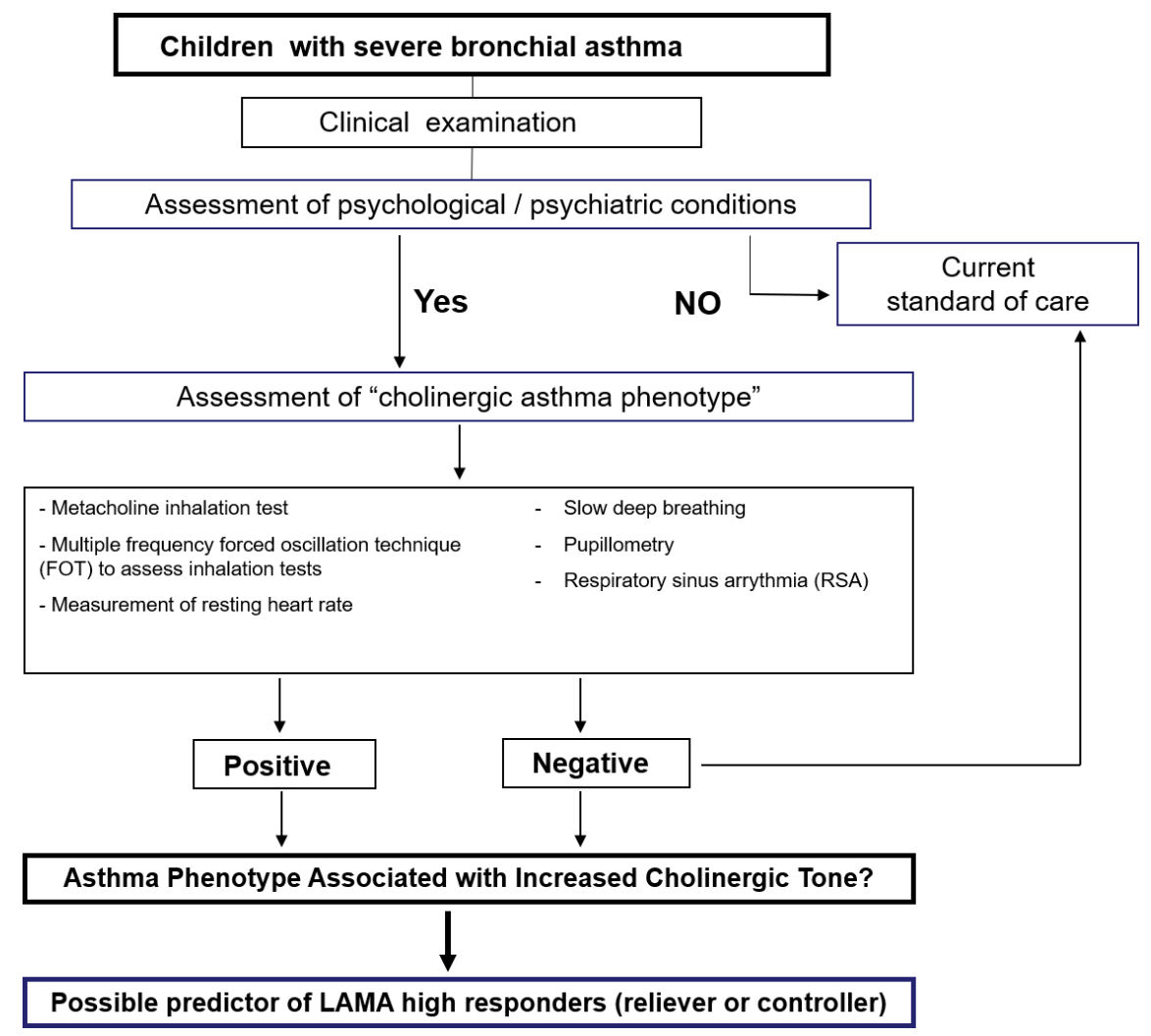

